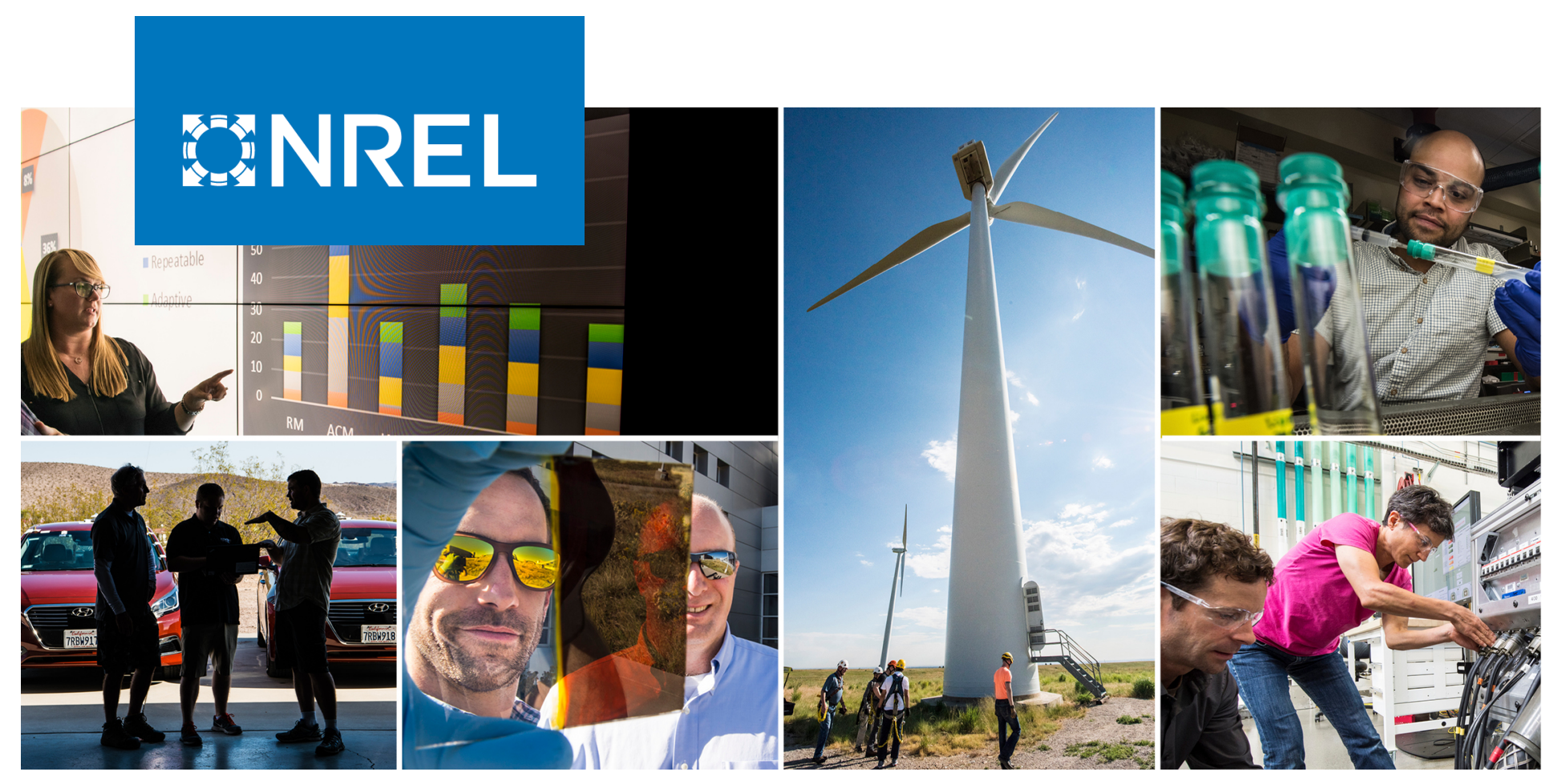

\title{
Integration of Storage in the DC Link of a Full Converter-Based Distributed Wind Turbine
}

\section{Preprint}

Ram Poudel, Venkat Krishnan, James Reilly, Przemyslaw Koralewicz, and lan Baring-Gould

National Renewable Energy Laboratory

Presented at the 2021 IEEE Power \& Energy Society General Meeting July 25-29, 2021

NREL is a national laboratory of the U.S. Department of Energy Office of Energy Efficiency \& Renewable Energy

Operated by the Alliance for Sustainable Energy, LLC

This report is available at no cost from the National Renewable Energy Laboratory (NREL) at www.nrel.gov/publications.
Conference Paper

NREL/CP-5000-78347

February 2021 


\title{
BNREL
}

\section{Integration of Storage in the DC Link of a Full Converter-Based Distributed Wind Turbine}

\section{Preprint}

\author{
Ram Poudel, Venkat Krishnan, James Reilly, \\ Przemyslaw Koralewicz, and lan Baring-Gould \\ National Renewable Energy Laboratory
}

\author{
Suggested Citation \\ Poudel, Ram, Venkat Krishnan, James Reilly, Przemyslaw Koralewicz, lan Baring-Gould. \\ 2021. Integration of Storage in the DC Link of a Full Converter-Based Distributed Wind \\ Turbine: Preprint. Golden, CO: National Renewable Energy Laboratory. NREL/CP-5000- \\ 78347. https://www.nrel.gov/docs/fy210sti/78347.pdf.
}

(C) 2021 IEEE. Personal use of this material is permitted. Permission from IEEE must be obtained for all other uses, in any current or future media, including reprinting/republishing this material for advertising or promotional purposes, creating new collective works, for resale or redistribution to servers or lists, or reuse of any copyrighted component of this work in other works.

NREL is a national laboratory of the U.S. Department of Energy Office of Energy Efficiency \& Renewable Energy Operated by the Alliance for Sustainable Energy, LLC

This report is available at no cost from the National Renewable Energy Laboratory (NREL) at www.nrel.gov/publications.

Contract No. DE-AC36-08GO28308
Conference Paper

NREL/CP-5000-78347

February 2021

National Renewable Energy Laboratory 15013 Denver West Parkway Golden, CO 80401

303-275-3000 • www.nrel.gov 


\section{NOTICE}

This work was authored by the National Renewable Energy Laboratory, operated by Alliance for Sustainable Energy, LLC, for the U.S. Department of Energy (DOE) under Contract No. DE-AC36-08GO28308. Funding provided by the U.S. Department of Energy Office of Energy Efficiency and Renewable Energy Wind Energy Technologies Office. The views expressed herein do not necessarily represent the views of the DOE or the U.S. Government. The U.S. Government retains and the publisher, by accepting the article for publication, acknowledges that the U.S. Government retains a nonexclusive, paid-up, irrevocable, worldwide license to publish or reproduce the published form of this work, or allow others to do so, for U.S. Government purposes.

This report is available at no cost from the National Renewable Energy Laboratory (NREL) at www.nrel.gov/publications.

U.S. Department of Energy (DOE) reports produced after 1991 and a growing number of pre-1991 documents are available free via www.OSTI.gov.

Cover Photos by Dennis Schroeder: (clockwise, left to right) NREL 51934, NREL 45897, NREL 42160, NREL 45891, NREL 48097, NREL 46526.

NREL prints on paper that contains recycled content. 


\title{
Integration of Storage in the DC Link of a Full Converter-Based Distributed Wind Turbine
}

\author{
Ram Poudel, Venkat Krishnan, Senior Member, IEEE, James Reilly, Przemyslaw Koralewicz, Ian Baring-Gould \\ National Renewable Energy Laboratory (NREL), Golden, CO, 80401, USA
}

\begin{abstract}
Energy storage is known to support the dispatchability of variable renewable resources. In this paper, we model a battery energy storage system (BESS) integrated with the DC link of a Type IV full converter-based wind turbine and the necessary controls to achieve efficient dispatch. To support the validation of control methodologies, we build a detailed model of a Type IV research wind turbine at the National Renewable Energy Laboratory (NREL), the Controls Advanced Research Turbine (CART 3), and we integrated a lithium-ion BESS model in gridfollowing mode into the model. The simulation results illustrate the sizing and control of the DC link-integrated BESS for a given variable wind resource and varying dispatch strategies (i.e., under constant, uncertain, and ramping wind scenarios). The integrated storage can smooth variabilities in distributed wind output, hedge against uncertainties, provide the ramping capability, as well as support stability under voltage and frequency transients. All of these have been illustrated in MATLAB/Simulink.
\end{abstract}

Index Terms-Distributed wind, Integrated storage, DC-link voltage, Voltage regulation, Frequency support, Detailed model

\section{INTRODUCTION}

The contribution of variable renewable energy resources is increasing in the portfolio of electricity generation nationwide, at both transmission and distribution systems. Wind energy is a major renewable resource in our generation portfolio, especially with large power plants at the transmission level. Distributed wind turbines are connected at distribution voltage levels and serve local loads. Distributed wind systems are installed for a variety of reasons - to increase energy security, to reduce utility bills, to mitigate energy price volatility, or simply to generate renewable energy [1]. With the increasing contribution and the offset of conventional generation sources, wind turbines are expected to produce dispatchable power to maintain or increase reliability and resilience, and to uphold acceptable ANSI voltage limits. One way to make a wind turbine dispatchable is to create a hybrid system with a battery energy storage system (BESS).

A BESS can be integrated with a wind turbine via either AC or DC coupling, each with its own topologies [2]. Several U.S. Department of Energy (DOE) Competitiveness Improvement Projects (CIPs) [3] are working to integrate energy storage with their systems to provide grid support services and resilience. In this paper, we investigate integration of a BESS at the DC link of a full converter (Type IV) distributed wind turbine. This way of integration is gaining traction among project developers because integration with the DC link uses the existing inverter (at the grid side) of a full-scale converter-based wind turbine, thereby enhancing economic viability [4].

A BESS integrated on the DC link between the converter and inverter of a Type IV wind turbine can be used to perform various control functions and grid services. The function of a BESS could range from improving power output quality at the terminals of the generating sources to compliance with the ramp rate constraints stipulated by the area grid code. Moreover, the same BESS can also be leveraged to meet forecasted power needs, economic dispatch, and the black start of the wind turbine in the event of power loss.

Past work on modeling BESS at the DC-link has considered various aspects of controls, sizing, and dispatch. Babazadeh et al. [5] developed a hybrid storage model linked to a $5 \mathrm{MW}$ wind turbine and considered supercapacitors for short-term variations and BESS for longer-term variations. The paper developed a method to switch the BESS based on a supercapacitor's state of charge (SOC), thereby reducing BESS cycling and extending life. This type of modeling was done earlier by Ullah et al. [6] for a distributed wind turbine; this research demonstrated the ability of hybrid storage to support a wind turbine's voltage ride-through. This work also demonstrated the use of supercapacitors to enhance the control of DC-link voltage, which enabled BESS to mitigate longerterm fluctuations. Mahod et al. developed a BESS control model [7] in MATLAB, where the converter was modeled as a voltage source to provide transient voltage support and power quality during a grid outage. Yuan et al. [8] developed a method for controlling Type IV wind turbine speed in response to transient voltage in weak grids, and they briefly alluded to sizing a larger DC-link capacitor to provide storage capability at the DC link to enhance voltage support capabilities.

In this paper, we applied a control strategy for a BESS at the DC link of Type IV distributed wind turbine at the NREL Flatirons Campus. The contribution of our work lays in the proposed extension of the DC link power balance equation [8] to include BESS, and the development of a detailed model in MATLAB Simulink to illustrate the control. We assess the capability of the BESS to enhance the dispatchability of a distributed wind turbine during varying wind speeds and unforeseen ramping and to investigate its ability to provide frequency and voltage support during disturbances. Using 20 $\mathrm{Hz}$ wind resource data from the M5 tower at the NREL campus [9], this paper enumerates various technical and wind variability considerations for sizing the BESS. Finally, the impact of the size of the grid-side converter on the ability to provide megawatt-frequency and volt-volt ampere reactive (var) support is studied. We believe this applied research will inform the distributed wind turbine developers on costeffective ways to comply with grid requirements using BESS.

\section{DisTRIBUTED WIND TURBINE AND BESS}

For this research, we use a three-bladed Controls Advanced Research Turbine (CART3) at NREL [10]. This 600-kW turbine, though recently decommissioned, was specially designed to study advanced control concepts with a customized and reprogrammable real-time controller; the controller is well 
documented in related literature, with ample recorded data to support the analysis. The CART3 employs the Type IV configuration [11] with a full-power converter system consisting of a rotor-side converter for maximum power extraction and a grid-side converter (GSC) for DC-link voltage control and independent real power $(\mathrm{P})$ and reactive power $(\mathrm{Q})$ control, thereby decoupling the wind turbine from the grid. We use a generic model of the CART3 in MATLAB/Simulink adapted from [12]. The model includes a customizable turbine, drivetrain, generator, and converters. We customized this model to represent the CART3 with a rated capacity of $600 \mathrm{~kW}$ at $11.7 \mathrm{~m} / \mathrm{s}$. A detailed specification of the CART3 turbine is provided here [13]. If $\mathrm{P}_{\mathrm{W}}(\mathrm{t})$ is the aerodynamic power available from the wind, we can relate this power to the power output from the generator, $\mathrm{P}_{\mathrm{g}}(\mathrm{t})$, by lumping the system inertia to $\mathrm{J}$, as shown in (1) and (2).

$$
\begin{aligned}
& \mathrm{P}_{\mathrm{W}}(\mathrm{t})-\mathrm{J} \omega \frac{d \omega}{d t}=\mathrm{P}_{\mathrm{g}}(\mathrm{t}), \\
& \mathrm{P}_{\mathrm{W}}(\mathrm{t})=\frac{1}{2} \eta \rho A u^{3} C p(\omega),
\end{aligned}
$$

where $\omega$ is the angular velocity of the high-speed shaft, $\rho$ is the density of air, $\mathrm{u}$ is the wind speed, $\eta$ is the efficiency, and $C p(\omega)$ is the power coefficient as a function of $\omega$ [8].

\section{A. Modeling BESS Integrated in the DC Link}

The power balance at the DC link of the wind turbine, without considering the BESS is given by (3). Fig. 1 shows the wind turbine model with the DC-link capacitor, C, the permanent magnet synchronous generator (PMSG) power, $\mathrm{P}_{\mathrm{g}}(\mathrm{t})$, load on the GSC, $\mathrm{P}_{\mathrm{L}}(\mathrm{t})$ (or the set-point command to the hybrid plant); and the BESS at the DC link via the DC to DC converter.

$$
\mathrm{P}_{\mathrm{g}}(\mathrm{t})-\mathrm{P}_{\mathrm{L}}(\mathrm{t})=\mathrm{d} \mathrm{E}_{\mathrm{c}} / \mathrm{dt} \text {. }
$$

We know $\mathrm{E}_{\mathrm{c}}=0.5 \mathrm{CV} V^{2}$; therefore, $\mathrm{dE}_{\mathrm{c}} / \mathrm{dt}=\mathrm{CV} \mathrm{dV} \mathrm{dc}_{\mathrm{dc}} / \mathrm{dt}=\mathrm{Q}$ $\mathrm{dV}_{\mathrm{dc}} / \mathrm{dt}$, where charge $\mathrm{Q}=\mathrm{CV}$. Hence:

$$
\mathrm{P}_{\mathrm{g}}(\mathrm{t})-\mathrm{P}_{\mathrm{L}}(\mathrm{t})=\mathrm{Q} d \mathrm{~V}_{\mathrm{dc}} / \mathrm{dt} \text {. }
$$

Considering the BESS connected in parallel with the capacitor, as shown in Fig. 1, (4) becomes:

$$
\mathrm{P}_{\mathrm{g}}(\mathrm{t})-\mathrm{P}_{\mathrm{L}}(\mathrm{t}) \pm \mathrm{P}_{\mathrm{b}}(\mathrm{t})=\mathrm{Q} d \mathrm{~V}_{\mathrm{dc}} / \mathrm{dt} \text {. }
$$

The + sign on the battery power, $\mathrm{P}_{\mathrm{b}}$, indicates discharging, and the - sign indicates charging. Substituting $\mathrm{P}_{\mathrm{g}}(\mathrm{t})$ into (1):

$$
\mathrm{P}_{\mathrm{W}}(\mathrm{t})-\mathrm{J} \omega \frac{d \omega}{d t}-\mathrm{P}_{\mathrm{L}}(\mathrm{t}) \pm \mathrm{P}_{\mathrm{b}}(\mathrm{t})=\mathrm{Q} \frac{d V_{d c}}{d t} .
$$

This is the governing equation of the power balance in the DC link. This is a nonlinear equation that relates the site characteristics (resource, load variability, and uncertainty), generator synchronizing power (related to the inertia and frequency change), and the dynamics of the DC voltage and battery. Given this is a Type IV turbine that is connected to the grid via an AC-DC rectifier, and then to the grid via a DC-AC inverter, the PMSG's synchronous speed is allowed to change, and variable-speed or variable AC frequency is converted to the grid frequency. A sudden change in the PMSG's speed, in response to the dynamics in the wind power, $\mathrm{P}_{\mathrm{w}}$, or commanded dispatch power, $\mathrm{P}_{\mathrm{L}}$, however, is reflected in the change in the PMSG's synchronizing power, which is proportional to the rate of change of speed - all of which impact the DC-link voltage. Typically, the GSC controls the $\mathrm{V}_{\mathrm{dc}}$ voltage; however, per (6) in this paper, by connecting the BESS parallel to the PMSG at the DC link, we let the BESS control the $\mathrm{V}_{\mathrm{dc}}$ (which is further explained in the next section). In effect, the battery charge or discharge depending on the GSC's output power.

i) For $P_{L}(t)>P_{g}(t)$, battery will be discharged.

ii) For $\mathrm{P}_{\mathrm{L}}(\mathrm{t})<\mathrm{P}_{\mathrm{g}}(\mathrm{t})$, battery will be charged.

\section{B. Battery Controller Design at the DC Link}

Assume $\mathrm{P}_{\mathrm{L}}(\mathrm{t}), \mathrm{P}_{\mathrm{w}}(\mathrm{t})$, and $\omega$ (or $\left.\mathrm{d} \omega / \mathrm{dt}\right)$ are constants in (6). Then, the use of the battery power, $\mathrm{P}_{\mathrm{b}}$, becomes proportional to the rate of change of the voltage across the capacitor $\left(\mathrm{V}_{\mathrm{dc}}\right)$ :

$$
\mathrm{P}_{\mathrm{b}}(\mathrm{t})=C V_{d c} \frac{d V_{d c}}{d t} .
$$

A transfer function from $V_{d c}$ to $\mathrm{P}_{\mathrm{b}}$ is:

$$
\frac{V_{d c(s)}}{\mathrm{P}_{b}(\mathrm{~s})}=\frac{1}{s C V_{d c}} \text {. }
$$

$$
\text { (8) }
$$

Given $\mathrm{P}_{\mathrm{b}}=\mathrm{i}_{\mathrm{b}} * \mathrm{~V}_{\mathrm{b}}$; for a constant battery voltage, $\mathrm{V}_{\mathrm{b}}$, we have:

$$
\frac{V_{d c(s)}}{\mathrm{ib}(\mathrm{s})}=\frac{V b}{V_{d c}} \frac{1}{s C} \text {. }
$$

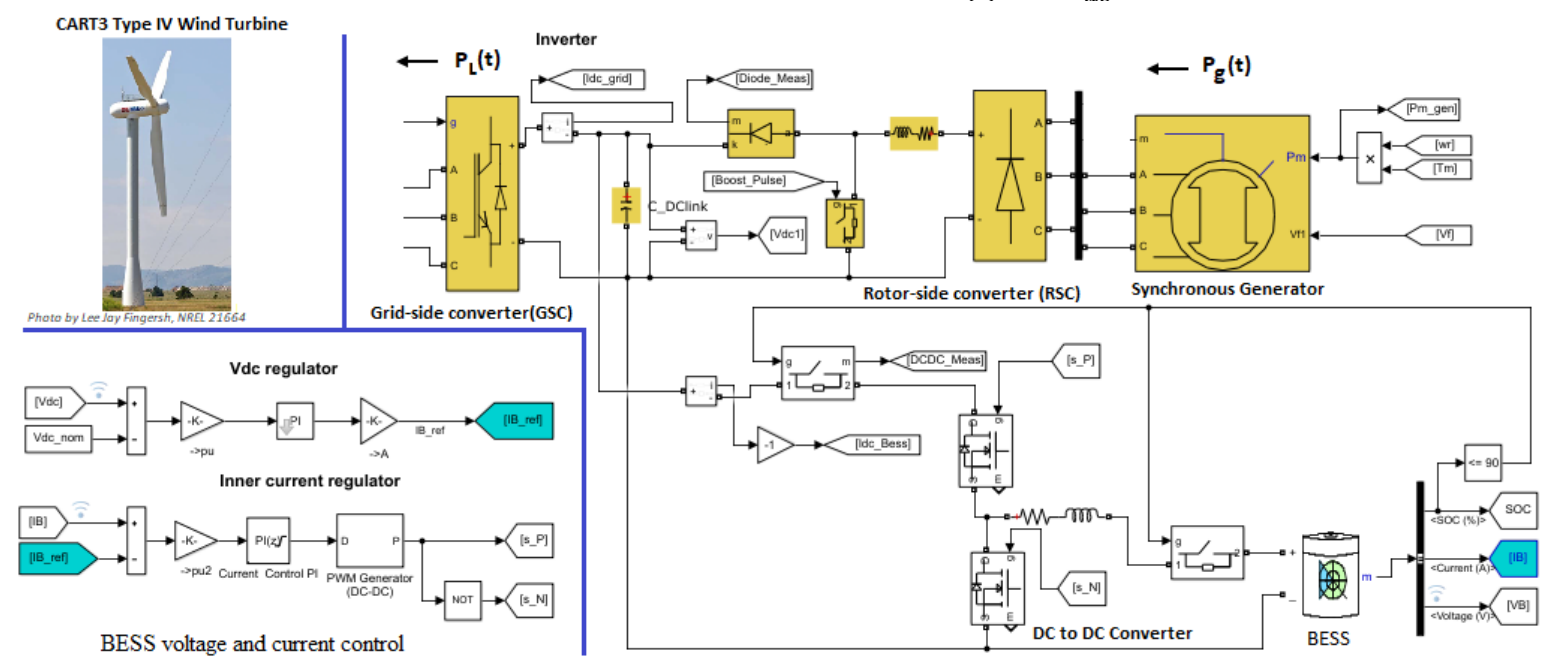

Fig. 1. MATLAB Simulink model of Type IV CART3 turbine at NREL, with BESS at the DC link (right); BESS voltage and current control (bottom left) 
Equation (9) suggests first-order dynamics between the $V_{d c}$ and battery current, $\mathrm{i}_{\mathrm{b}}$ [14]. Accordingly, a reference value of $\mathrm{i}^{*}{ }_{\mathrm{b}}$ can be generated using a proportional-integral (PI) controller that responds to the error function, $\left(V_{d c}^{n o m}-V_{d c}\right)$. We use outer voltage feedback control and inner current control to generate a reference current for the battery, as shown in Fig. 1. The DC to DC converter uses a pulse width modulator (PWM) generator [15]. The nominal DC voltage is $1,100 \mathrm{~V}$, and the PI parameters used are $[\mathrm{Kp} \mathrm{Ki}]=\left[\begin{array}{ll}1.5 & 200\end{array}\right]$ and $\left[\begin{array}{ll}0.5 & 10\end{array}\right]$ for the voltage and current regulators, respectively. The pulses, s_P and s_N, generated by the PWM generator are used by the $\overline{\mathrm{DC}}$ to $\mathrm{DC}$ converter of the BESS. In this model, we made the $\mathrm{V}_{\mathrm{dc}}$ control adaptive-i.e., when the SOC is within $10 \%-90 \%$, the BESS responds to any fluctuations in the $V_{d c}$ ( \pm dead-band), and outside these SOC limits, the wind turbine GSC controls the $\mathrm{V}_{\mathrm{dc}}$ for stability.

\section{BATTERY SIZING For A GIVEN Wind RESOURCE}

The sizing of the integrated storage depends on the wind power variability and uncertainty, the dispatch strategy, and the inverter size. It also depends on other factors, including life-cycle parameters, battery health, economic cost-benefit ratio, and payback period. Such a detailed techno-economic sizing analysis is beyond the scope of this paper; however, here we use wind resource and plausible hybrid dispatch strategies to make a good initial estimate of the size.

Given that the aim of this effort is to size a battery that can be integrated at the wind turbine's DC link, we size the battery with the aim to make the wind turbine dispatchable-i.e., to (1) smooth the power fluctuations, (2) smooth the ramp, and (3) follow a set point. We use time-series data sampled at 20 $\mathrm{Hz}$ from a meteorological tower known as the M5 tower [9] that is closer to the CART3 turbine at NREL's Flatirons Campus. Let $\mathrm{P}_{\text {hybrid }}$ be the power dispatch at the terminal of the wind turbine, i.e.,

$$
\mathrm{P}_{\text {hybrid }}(\mathrm{t})=\mathrm{P}_{\mathrm{g}}(\mathrm{t})+\mathrm{P}_{\mathrm{b}}(\mathrm{t}) \text {. }
$$

The wind resource time-series data are run through the power curve of the CART3 to estimate the available aerodynamic power, $\mathrm{P}_{\mathrm{w}}$. To get an estimate of the BESS sizing, we use $\mathrm{P}_{\mathrm{w}}$ as a proxy for $\mathrm{P}_{\mathrm{g}}$ in (10). For $\mathrm{P}_{\text {hybrid values, we }}$ assume three plausible dispatch cases with time window $\mathrm{T} \mid \mathrm{T}$ $\in\{1,5,10,30,60$ minutes $\}$. Fig. 2 presents the example dispatch for these three cases with $\mathrm{T}=10$ minutes.

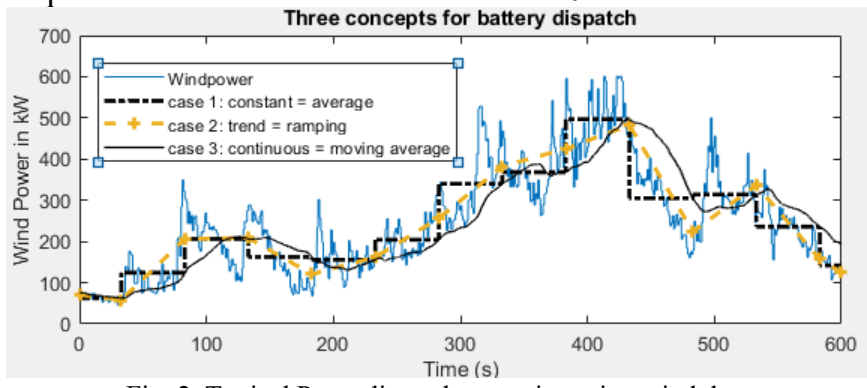

Fig. 2. Typical $\mathrm{P}_{\text {hybrid }}$ dispatch scenarios using wind data

Case 1: Constant $\boldsymbol{P}_{\text {hybrid }}$ dispatch for a given time window with dispatch equal to the average value for given $\mathrm{T}$. This dispatch ensures dispatchability and smooths the variations.
Case 2: Ramping $\boldsymbol{P}_{\text {hybrid }}$ dispatch, where the hybrid power follows a ramp, $\mathrm{P}_{\text {hybrid }}=\mathrm{A} \mathrm{P}(\mathrm{t})+\mathrm{B}$, with $\mathrm{A}$ (slope) and $\mathrm{B}$ (intercept or initial value) being constants for a given time window and estimated using a constrained least-squares method [16]. This dispatch smooths the ramps.

Case 3: Continuous $\boldsymbol{P}_{\text {hybrid }}$ dispatch, where the dispatch is estimated using a trailing moving average time window of $\mathrm{T}$.

There are two aspects of BESS sizing: power and energy rating. For a time-window of T, we estimate the BESS power and energy requirements using (11) and (12).

$$
\begin{aligned}
& \mathrm{P}_{\mathrm{BESS}}=\left\{\mathrm{P}_{\mathrm{GSC}}, \max \left(\mathrm{P}_{\mathrm{b}}{ }^{*}\right), \operatorname{mean}\left(\mathrm{P}_{\mathrm{b}}{ }^{*}\right), 95-99 \% \text { tile }\left(\mathrm{P}_{\mathrm{b}}{ }^{*}\right)\right\} \mathrm{kW} .(11) \\
& \mathrm{E}_{\mathrm{BESS}}=\frac{1}{2} \sqrt{\int_{0}^{T}\left[\mathrm{P}_{\text {hybrid }}-\mathrm{P}_{\mathrm{W}}\right]^{2} d t} \mathrm{kWh} .
\end{aligned}
$$

From (10), an estimate of $\mathrm{P}_{\mathrm{b}}{ }^{*}(\mathrm{t})$ can be |Phybrid(t) $\mathrm{Pw}(\mathrm{t}) \mid$. Depending on the use case and the economic viability, the power rating could be informed by several metrics, as shown in (11)-i.e., the maximum possible dispatch that is limited by the size of the GSC, or the maximum, average, or $95^{\text {th }}-99^{\text {th }}$ percentile (\%tile) of the estimated variability in the dispatch caused by the wind variability. For this study, we simulate using a BESS with a GSC capacity of $660 \mathrm{~kW}$ (at unity power factor) - i.e., $10 \%$ more than the rated capacity of the wind turbine.

For energy rating estimation, under dispatch cases 1 and 2, the net energy transaction for a period $\mathrm{T}$ is typically zero; hence, we use a half of the Euclidian norm of $\mathrm{P}_{\mathrm{b}}{ }^{*}(\mathrm{t})$ as a metric to estimate the energy rating, $\mathrm{E}_{\mathrm{BESS}}$, of the battery. The half in (12) accounts for the Pw fluctuations on the two sides of the battery dispatch, in general. The EBEss is a monotonically increasing function of time window T. Fig. 3 presents variations of $\mathrm{E}_{\mathrm{BESS}}$ for $\mathrm{T}=10 \mathrm{~min}$ for the entire day of May 20, 2020, at NREL's Flatirons Campus.

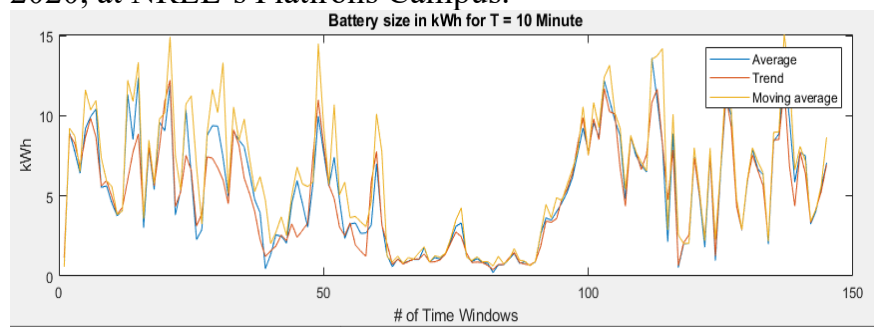

Fig. 3. EBEss estimated every 10 min, May 20, 2020 (144-time windows)

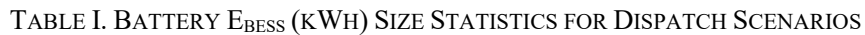

\begin{tabular}{|l|c|c|c|c|c|c|}
\hline \multirow{2}{*}{$\begin{array}{l}\text { Time } \\
\text { (T) }\end{array}$} & \multicolumn{2}{|c|}{ Case 1: Average } & \multicolumn{2}{c|}{ Case 2: Ramp } & \multicolumn{2}{c|}{ Case 3: Continuous } \\
\cline { 2 - 7 } Max & Avg & Max & Avg & Max & Avg \\
\hline 1 min & 2.27 & 0.51 & 2.00 & 0.49 & 2.77 & 0.61 \\
\hline 5 min & 5.93 & 1.61 & 4.51 & 1.55 & 6.13 & 1.85 \\
\hline 10 min & 6.80 & 2.61 & 6.11 & 2.49 & 7.54 & 3.07 \\
\hline 30 min & 12.67 & 5.75 & 10.22 & 5.50 & 16.85 & 6.90 \\
\hline 1 hour & 21.97 & 9.32 & 17.94 & 8.99 & 25.79 & 11.66 \\
\hline
\end{tabular}

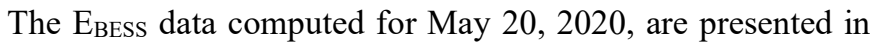
Table I for a set of $\mathrm{T}$ under three dispatch cases, each differing in the amount of variability left for the battery to pick up. The ramping dispatch (Case 2) requires the lowest $\mathrm{E}_{\mathrm{BESS}}$ size of the battery, while the Case 3 moving average tends to return a larger capacity battery because it does not involve forecasts. A user could size $\mathrm{E}_{\mathrm{BESS}}$ considering a relevant time duration and 
constraints associated with the battery management system, such as the depth-of-discharge.

\section{Simulation ReSUlts AND Discussion}

The results illustrate the control capability of the BESS connected at the DC link of Type IV CART3 turbine, and demonstrate the ability to smooth the wind power fluctuations and ramping, rendering the turbine dispatchable under various scenarios. We also show the ability of the BESS to improve the voltage and frequency support during transients.

\section{A. Scenario 1: Enhanced Power Control}

This scenario shows that the control system allows for the injection of power beyond that available from the wind. Fig. 4 presents a constant wind speed scenario of $11 \mathrm{~m} / \mathrm{s}$ with approximately 0.6-p.u. power. The BESS control responds to a frequency event of step equal to $-0.2 \mathrm{~Hz}$ at $8 \mathrm{~s}$ by increasing the hybrid power to 1.1 p.u., the maximum limit of the GSC. With a step change of 0.5 p.u. $(300 \mathrm{~kW})$ in power in response to the frequency event, the $\mathrm{V}_{\mathrm{dc}}$ dips to $\sim 1,075 \mathrm{~V}$, a $2.3 \%$ deviation from the nominal value of $1,100 \mathrm{~V}$. Given the active power priority mode, the reactive power, $\mathrm{Q}$, changed from a negative to a positive value to reflect the apparent power constraints. Scenario 1 shows that without the integrated storage, wind provides $360 \mathrm{~kW}$; and with the BESS, total power of $660 \mathrm{~kW}$ is available to enhance energy dispatch and to arrest any frequency events.

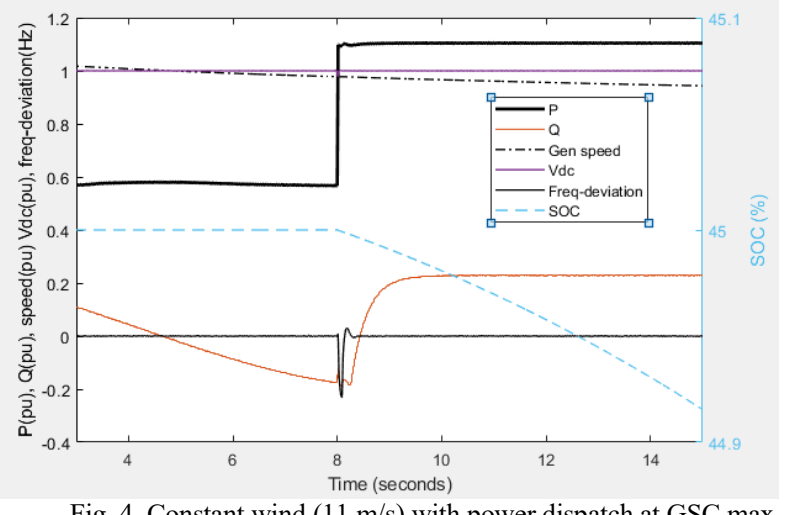

Fig. 4. Constant wind $(11 \mathrm{~m} / \mathrm{s})$ with power dispatch at GSC max

\section{B. Scenario 2: Forecasted Wind Variability}

Here, we present results for the case where $P_{\text {hybrid }}$ comprises both a constant and ramping dispatch under varying wind power, as shown in Fig. 5. For time $t=[5,15] \mathrm{s}$, the $\mathrm{P}_{\text {hybrid }}$ is constant and less than the $\mathrm{P}_{\mathrm{w}}$. At $15 \mathrm{~s}$, we ramp up $\mathrm{P}_{\text {hybrid }}$ to the maximum capacity of the GSC converter when there is a forecasted ramp-up in the wind power; and at $23 \mathrm{~s}$, we ramp down the $\mathrm{P}_{\text {hybrid }}$ gradually based on the forecasted wind. Note that this illustration assumes a perfect forecast. With forecast errors, a look-ahead dispatch strategy can use the illustrated capability to mitigate ramps. The variation of the SOC is plotted along the right vertical axis. The positive P-BESS power is discharge and the negative is the charge in Fig. 5. From point $\mathrm{E}$ to $\mathrm{B}$, the wind power ( $\mathrm{P}$-wind) is ramping up at about $170 \mathrm{~kW} / \mathrm{s}$. The addition of the BESS helped to reduce the ramp to $62 \mathrm{~kW} / \mathrm{s}$ by a controlled ramp from $\mathrm{A}$ to $\mathrm{B}$. Similarly, the ramp-down rate of wind power from $\mathrm{C}$ to $\mathrm{F}$ is reduced by dispatching $\mathrm{P}_{\text {hybrid }}$ along the $\mathrm{C}$-to-D ramp trajectory.

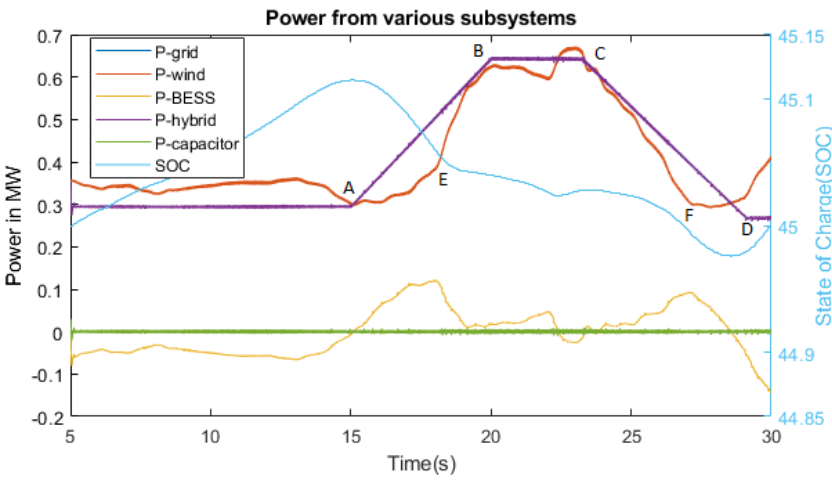

Fig. 5. Dispatch under varying wind conditions and ramp smoothing

C. Scenario 3: Frequency and Voltage Support

We demonstrate frequency, $\mathrm{f}$, and voltage, $\mathrm{V}$, support using f-P droop of $0.5 \%$, and $\mathrm{V}-\mathrm{Q}$ droop of $5 \%$. A V-Q droop of $5 \%$ implies that for a $5 \%$ change in voltage, a $100 \%$ change in reactive power, Q, was extracted. Fig. 6 presents a sketch of the V-Q droop implementation. The additional reactive power, $\mathrm{Qpu}$ _droop, was added to the reference reactive current of the GSC control system.

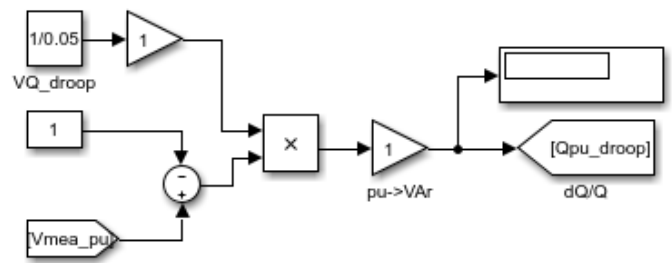

Fig. 6 Droop implementation for volt-var support (f-P support is also similar)

The actual delivery of the power, however, can be limited by the available headroom or the current state of the integrated storage. Similarly, the f-P droop was involved, adding the additional real power to the real power reference current of the GSC control.
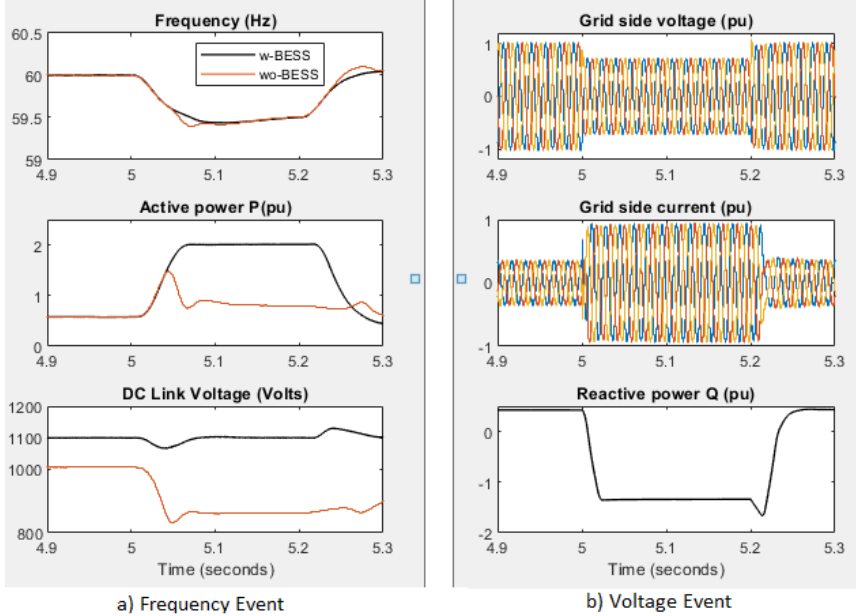

Fig. 7. Active and reactive power responses for frequency and voltage events

A frequency event of step $-0.5 \mathrm{~Hz}$ was applied at $5 \mathrm{~s}-5.2$ s. For this simulation, we use $\mathrm{E}_{\mathrm{BESS}}=1330 \mathrm{Ah}$ (with the same nominal voltage of $800 \mathrm{~V}$ ) and $\mathrm{P}_{\mathrm{GSC}}=1.2 \mathrm{MW}$ (i.e., 2.2 times the wind turbine rating). For the frequency event, the control system responded with a maximum active power response of 
1.2 MW from the oversized GSC. Fig. 7 (a) presents the response of the wind turbine in terms of $\mathrm{P}$ and the $\mathrm{Vdc}$ with or without BESS. This study also shows that by oversizing the GSC, we can exploit the BESS even further for the frequency response, which is otherwise not possible from a stand-alone wind turbine or GSC sized for the wind turbine. With the BESS-supporting frequency, the output of the wind turbine system is more reliable and predictable, and also reduces wind curtailment while operating flexibly. Fig. 7 (b) presents the responses to a voltage event with the BESS. A voltage fault at $75 \%$ of the nominal value was created by reducing the amplitude of the fundamental harmonic. Reactive power of approximately $1 \mathrm{MVAr}$ was extracted from the turbine with the integrated storage. The oversized inverter with the BESS helps to arrest the voltage event with large reactive power and has the capability to provide more fault current for protecting and clearing faults.

\section{CONCLUSIONS AND FUtURE WORK}

This paper presented a MATLAB Simulink model for the integration of a BESS at the DC link of a Type IV full converter wind turbine. All scenarios used the BESS in gridfollowing mode. We demonstrated that the BESS can be sized across three scenarios considering the wind resource and variability; the control can be used to ensure that the wind turbine can provide dispatchable power, smooth variations, hedge against uncertainties, provide the ramping capability, and enhance support under-voltage and frequency transients. The presence of integrated storage allows the capture of wind power that might otherwise be curtailed to provide these essential reliability services. Although the modeling undertaken shows that very limited storage capacity is needed to provide turbine specific benefits, the value and eventual size of integrated storage may also be driven by other system values beyond those studied in this paper.

Batteries can differ significantly with respect to the response time and ramp rate capabilities. In this study we modeled the Li-ion battery characteristics available in the NREL campus; however future works could evaluate the impact of varying battery characteristics for a wider range of battery types on the control performance and dispatchability of the type IV distributed wind turbine. A distributed wind turbine along with an oversized GSC and appropriately sized integrated storage can also speed system restoration by providing much-needed voltage support and frequency regulation during the gradual load pickup and line/transformer energization. Such an oversized system, along with a grid-forming inverter, can also enable the black start. The DC-link control developed in this paper for BESS integration can be expanded further to include the grid-forming control mode for the GSC in our future investigations, to analyze the value for grid resilience and black start in microgrid applications.

\section{ACKNOWLEDGMENTS}

This work was authored by the National Renewable Energy Laboratory, operated by Alliance for Sustainable Energy, LLC, for the U.S. Department of Energy under Contract No. DEAC36-08GO28308. Funding provided by the U.S. Department of Energy Wind Energy Technologies Office for the Microgrids, Infrastructure Resilience, and Advanced Controls Launchpad (MIRACL) project. The views expressed in the article do not necessarily represent the views of the DOE or the U.S. Government. The U.S. Government and the publisher, by accepting the article for publication, acknowledges that the U.S. Government retains a nonexclusive, paid-up, irrevocable, worldwide license to publish or reproduce the published form of the work, or allow others to do so, for U.S. Government purposes.

\section{REFERENCES}

[1] A. Orrell, D. Preziuso, N. Foster, S. Morris and J. Homer, "2018 Distributed Wind Market Report," Pacific Northwest National Laboratory, 2018.

[2] K. Das, M. Altin and E. N. Martinez, "Dynamic Modelling of WindSolar-Storage Based Hybrid Power Plant.," in Proceedings of the 18th Wind Integration Workshop, 2019.

[3] Office of Energy Efficiency \& Renewable Energy, "U.S. Distributed Wind Manufacturers Selected to Advance Wind Technologies and Grid Support Capabilities through DOE Competitiveness Improvement Project," EERE Articles, 11 August 2020.

[4] General Electric Company, "Hybrid Solutions," 2017.

[5] H. Babazadeh, W. Gao and X. Wang, "Controller Design for a Hybrid Energy Storage System Enabling Longer Battery Life in Wind Turbine Generators," in North American Power Symposium, Boston, MA, 2011.

[6] N. R. Ullah, J. Groot and T. Thiringer, "The Use of a Combined Battery/Supercapacitor Storage to Provide Voltage Ride-Through Capability and Transient Stabilizing Properties by Wind Turbines," in ESSCAP, Belfort, France, 2004.

[7] S. W. Mohod, S. M. Hatwar and M. V. Aware, "Grid Support with Variable Speed Wind Energy System and Battery Storage for Power Quality," Energy Procedia, vol. 12, pp. 1032-1041, 2011.

[8] X. Yuan, F. Wang, D. Boroyevich, Y. Li and R. Burgos, "DC-link Voltage Control of a Full Power Converter for Wind Generator Operating in Weak-Grid Systems," IEEE Transactions on Power Electronics, vol. 24, no. 9, pp. 2178-2192, 2009.

[9] National Renewable Energy Laboratory, "NWTC Turbine Inflow Towers: M5 / Site 4.0 Tower," [Online]. Available: https://wind.nrel.gov/MetData/M5Twr/. [Accessed 15 September 2020].

[10] L. J. Fingersh and K. Johnson, "Controls Advanced Research Turbine (CART) Commissioning and Baseline Data Collection," National Renewable Energy Laboratory, Golden, CO, 2002.

[11] X. Wang, D. W. Gao, J. Wang, W. Yan, W. Gao, E. Muljadi and V. Gevorgian, "Implementations and Evaluations of Wind Turbine Inertial Controls With FAST and Digital Real-Time Simulations," IEEE Transactions on Energy Conversion, vol. 33, no. 4, 2018.

[12] R. Gagnon and J. Brochu, "Wind Farm - Synchronous Generator and Full Scale Converter (Type 4) Detailed Model," The MathWorks, Inc. [Online]. [Accessed 15 September 2020].

[13] T. Ashuri, M. A. Rotea, Y. Xiao, Y. Li and C. V. Ponnurangam, "Wind Turbine Performance Decline and its Mitigation via Extremum Seeking Controls," American Institute of Aeronautics and Astronautics, 2016.

[14] Z. Jiang and X. Yu., "Modeling and control of an integrated wind power generation and energy storage system.," IEEE Power \& Energy Society General Meeting, 2009.

[15] E. Irmak, N. Güler, E. Kabalc and A. Calpbinici, "A Modified Droop Control Method for PV Systems in Island Mode DC Microgrid," 8th International Conference on Renewable Energy Research and Applications (ICRERA), Brasov, Romania, 2019.

[16] W. Wang, C. Mao, J. Lu and D. Wang, "An energy storage system sizing method for wind power integration," Energies, vol. 6, no. 7, pp. 33923404, 2013. 